\title{
Collecting Duct (Bellini Duct) Renal Cell Carcinoma: Oncologic Outcome and Therapeutic Management
}

\author{
Yuejun Du',2, Sascha Pahernik3 ${ }^{3}$, Matthias Kwol'3 , Stefan Fuxius', Boris Hadaschik', Dogu Teber', \\ Stefan Duensing5, Annette Kaiser, ${ }^{6}$, Markus Hohenfellner ${ }^{1}$, Carsten Grüllich ${ }^{7 *}$ \\ ${ }^{1}$ Department of Urology, Heidelberg University Hospital, Heidelberg, Germany \\ ${ }^{2}$ Department of Urology, Nanfang Hospital of Southern Medical University, Guangzhou, China \\ ${ }^{3}$ Department of Urology, Nuremberg General Hospital, Paracelsus Medical University, Nuremberg, Germany \\ ${ }^{4}$ Praxis for Onkologie, Heidelberg, Germany \\ ${ }^{5}$ Section of Molecular Urooncology, Department of Urology, Heidelberg University Hospital, Heidelberg, Germany \\ ${ }^{6}$ Clinic for Pathology, Nuremberg General Hospital, Paracelsus Medical University, Nuremberg, Germany \\ ${ }^{7}$ Department of Medical Oncology, National Center for Tumor Diseases, Heidelberg University Hospital, Heidelberg, Germany \\ Email: *carsten.gruellich@med.uni-heidelberg.de
}

How to cite this paper: Du, Y.J., Pahernik, S., Kwol, M., Fuxius, S., Hadaschik, B., Teber, D., Duensing, S. Kaiser, A., Hohenfellner, M. and Grüllich, C. (2017) Collecting Duct (Bellini Duct) Renal Cell Carcinoma: Oncologic Outcome and Therapeutic Management. Journal of Cancer Therapy, 8, 413-422.

https://doi.org/10.4236/jct.2017.85036

Received: April 13, 2017

Accepted: May 15, 2017

Published: May 18, 2017

Copyright $\odot 2017$ by authors and Scientific Research Publishing Inc. This work is licensed under the Creative Commons Attribution International License (CC BY 4.0).

http://creativecommons.org/licenses/by/4.0/ (c) (i) Open Access

\begin{abstract}
Objectives. To evaluate treatment and prognosis of collecting duct renal cell carcinoma (CDRCC) in three institutions. Methods. The data of CDRCC patients were collected retrospectively from 3 participating institutions. Results: A total of 24 patients were identified in 3 institutions with an incidence of $0.5 \%-0.6 \%$. Among them, the median age was 63.0 years and male gender was predominant $(66.7 \%)$. At least $45.7 \%$ (11/24) of the patients were symptomatic at presentation. Moreover, distant metastasis at initial diagnosis was present in 13 patients $(54.2 \%)$ and 6 patients (25.0\%) developed distant metastasis during the course of disease. Almost all these patients were at high stage (87.5\%) and poorly differentiated (79.2\%). Besides, nodal involvement and major vein extension were observed in 14 (58.3\%) and $10(41.7 \%)$ patients, respectively. All the patients in this cohort underwent surgery with a median cancer specific survival of 11.3 months. Of the 14 patients with chemotherapy, gemcitabine/cisplatin was dominantly given in 6 patients (42.9\%). Conclusions: CDRCC is rarely seen. Most of CDRCC patients had advanced stage, high nuclear grade, regional nodal involvement, distant metastasis at presentation and consequent poor prognosis. To date, no standard protocol for the treatment of CDRCC exists. Current standard in systemic therapy of CDRCC is chemotherapy with gemcitabine and cisplatin.
\end{abstract}

\section{Keywords}

Bellini Duct, Collecting Duct, Prognosis, Renal Cell Cancer, Treatment 


\section{Introduction}

Renal cell carcinoma (RCC), which is the 7th most common cancer in men and the 9 th most common in women, accounts for $2 \%-3 \%$ of all malignant tumors in adults [1]. In 2012, there were 84,400 new cases of RCC and 34,700 kidney cancer-related deaths in the European Union [2]. The most common histological subtype of RCC is clear cell (70\% - 80\%), followed by papillary (10\% - 15\%) and chromophobe (3\% - 5\%), respectively. Besides, some other uncommon subtypes consist of approximately the remaining $5 \%$ of cases [1] [3]. Among them, collecting duct (Bellini duct) renal cell carcinoma (CDRCC) is an extremely rare RCC variant with a very low frequency ranging from $0.4 \%$ to $1.8 \%$ of all RCCs [4]. CDRCC is considered to arise from the collecting ducts in the medulla pyramid. CDRCC is usually centrally located, whitish in color and poorly defined with a high frequency of invading neighboring fat and vessels. Microscopically, the typical histologic features of CDRCC are of irregular tubular or tubulopapillary architecture, high nuclear grade and desmoplastics troma with numerous neutrophils. Regarding immunoh is to chemical staining, cells of CDRCC are generally positive for HMWCK, UEA-1 as well as coexpression of low and high molecular weight cytokeratins (CKs), such as CK7, CK19, etc, while none of these markers are definitive [3] [4] [5]. Although there are no specific imaging tools so far, several computed tomography (CT)findings may implicate CDRCC, which include medullary location, weak and hetero generous enhancement, involvement of the renal sinus, infiltrative growth, preserved renal contour, and a cystic component [6] [7] [8].

In the literature, the majority of CDRCC patients were symptomatic and metastatic at presentation, consequently had a poor prognosis [9] [10] [11]. To date, there is no standard therapy for this rare condition.

Although most of reported patients with CDRCC have under gonesurgery, radical nephrectomy alone seems not to favor the prognosis of the metastatic cases except for cytoreductive or palliative reasons. Of note, the invasive nature of CDRCC along with the poor preoperative performance status of these patients tends to increase the risk of perioperative morbidity and mortality. Accordingly, surgical treatment for known CDRCC patients should be individualized. Although efficacy of immune therapy has been reported in a few small series, it is considered to be not effective in treatment of metastatic CDRCC. However, some cases receiving chemotherapy with a gemcitabine-cisplatin (G/C) regimen were reported to achieve stabilization or partial remission and beneficial palliation. Following the continuous improvement of the understanding of the molecular mechanisms underlying RCC, the advent of targeted agents has dramatically altered therapeutic landscape of RCC and significantly improved oncological outcome of the patients. However, no evidence except a few small series or case reports supports the efficacy of targeted therapy for CDRCC so far. Accordingly, several trials are under way to evaluate the role of targeted therapies in non-clear cell RCC [6] [12] [13] [14].

The aim of this study is to describe and evaluate the patient and tumor cha- 
racteristics, treatment modalities and oncological outcome of CDRCC in three institutions.

\section{Methods}

\subsection{Data Collection}

Due to the rarity of the disease patients with CDRCC were extracted from institutional database of 3 participating institutions, including Dept. of Urology in Heidelberg University Hospital (1990-2015), Dept. of Urology in Nuremberg General Hospital (2007-2016) and Dept. of Medical Oncology in National Center for Tumor Diseases Heidelberg (2007-2015). The demographic, clinical, pathological and laboratory information of the patients were collected retrospectively.

\subsection{Pathological Findings}

Diagnosis of CDRCC was made based on the examination of surgical specimens. All the surgical specimens were processed according to standard pathologic procedures and evaluated by an experienced genitourinary pathologist. Tumor histology was stratified according to 2004 WHO classification of renal tumors. [4] Pathologic stage was reassigned according to the 2009 American Joint Committee on Cancer TNM staging system. Tumor cell differentiation was assessed according to Fuhrman nuclear grade.

\subsection{Follow-Up and Assessment}

After a baseline visit, the patients were followed every 3 to 6 months for 5 years or until death. At every visit, history, physical examination, routine blood workup, and radiographic evaluation were assessed. In addition, scintigraphy and brain imaging was performed, if there was a specific suspicion in the presence of symptoms. Therapeutic options including surgery for primary and metastatic lesion, chemotherapy, radiation therapy, cytokine therapy and targeted therapy were evaluated. Cancer specific survival (CSS) was calculated from initial diagnosis of CDRCC to death from CDRCC or was censored at the date of last follow-up.

\section{Results}

A total of 24 CDRCC patients were identified in 3 institutions. Among them, 11 patients $(0.5 \%)$ were extracted from 2046 patients undergoing surgery for RCC in Heidelberg University Hospital, 5 patients $(0.6 \%)$ were extracted from 831 patients in Nuremberg General Hospital and 8 patients were extracted in National Center for Tumor Diseases Heidelberg.

\subsection{Patients and Tumor Characteristics}

As shown in Table 1, median age of the patients was 63.0 years old and male gender was predominant (66.7\%) in this cohort. All were of Caucasian origin. Of 
these patients, $11(45.7 \%)$ were symptomatic at presentation including 5 with pain in flank or metastatic site and 6 with gross hematuria. Five patients $(20.8 \%)$ were asymptomatic, whereas in 8 patients $(33.3 \%)$ this information was not available. Missing information a was due to a lack in documentation. In the entire cohort, distant metastasis at initial diagnosis was present in 13 patients (54.2\%) and 6 patients (25.0\%) developed distant metastasis during the course of disease. The most common metastatic site was lung $(n=8)$ and bone $(n=8)$, followed by lymph nodes in distant sites $(n=7)$ and liver $(n=5)$. Of the patients with distant metastasis, $57.9 \%(11 / 19)$ of patients had solitary metastasis, while the remaining $42.1 \%(6 / 19)$ had two or more metastases. Besides, local recurrence was occurred in 5 patients $(20.8 \%)$. The tumor characteristics of 24 patients were listed in Table 2. Outside of a few patients with missing data, almost all the CDRCC patients were at high stage $(87.5 \%)$ and were poorly differentiated (79.2\%). Moreover, nodal involvement and major vein extension were observed in $58.3 \%(14 / 24)$ and $41.7 \%(10 / 24)$ of the patients, respectively.

Table 1. Characteristics of 24 patients with collecting duct renal cell carcinoma (CDRCC).

\begin{tabular}{|c|c|}
\hline Characteristics & Description \\
\hline Median age at diagnosis, years (range) & $63.0(22.4-82.8)$ \\
\hline Male Gender, n (\%) & $16(66.7 \%)$ \\
\hline \multicolumn{2}{|l|}{ ECOG, n (\%) } \\
\hline 0 & $8(33.3 \%)$ \\
\hline 1 & $8(33.3 \%)$ \\
\hline 2 & $1(4.2 \%)$ \\
\hline NA & $7(29.2 \%)$ \\
\hline \multicolumn{2}{|l|}{ Laterality of primary tumor, $n .(\%)$ : } \\
\hline Left & $9(37.5 \%)$ \\
\hline Right & $15(62.5 \%)$ \\
\hline \multicolumn{2}{|l|}{ Symptomatic at presentation, n. (\%) } \\
\hline Yes & $11(45.7 \%)$ \\
\hline Gross hematuria & $5(20.8 \%)$ \\
\hline Pain & $6(25.0 \%)$ \\
\hline No & $5(20.8 \%)$ \\
\hline NA & $8(33.3 \%)$ \\
\hline \multicolumn{2}{|l|}{ Local recurrence, n. (\%) } \\
\hline Yes & $6(25.0 \%)$ \\
\hline No & $18(75.0 \%)$ \\
\hline \multicolumn{2}{|l|}{ Metastatic status, n. (\%) } \\
\hline Synchronic & $13(54.2 \%)$ \\
\hline Metachronic & $6(25.0 \%)$ \\
\hline No metastasis & $5(20.8 \%)$ \\
\hline \multicolumn{2}{|l|}{ Number of metastases, n (\%) } \\
\hline Solitary & $11(45.7 \%)$ \\
\hline multiple & $8(33.3 \%)$ \\
\hline \multicolumn{2}{|l|}{ Sites of concomitant metastases } \\
\hline Lung & $8(33.3 \%)$ \\
\hline Bone & $8(33.3 \%)$ \\
\hline Lymph nodes & $7(29.2 \%)$ \\
\hline Liver & $5(20.8 \%)$ \\
\hline Other organs & $6(25.0 \%)$ \\
\hline
\end{tabular}


Table 2. Pathological characteristics of the tumors in 24 patients with collecting duct renal cell carcinoma (CDRCC).

\begin{tabular}{|c|c|}
\hline Characteristics & Description \\
\hline${ }^{\dagger}$ Median tumor size, $\mathrm{cm}$ (range), $\mathrm{n}=18$ & $5.5(1.0-12.0)$ \\
\hline \multicolumn{2}{|l|}{ T stage, n. (\%): } \\
\hline $1 b$ & $2(8.3 \%)$ \\
\hline $3 a$ & $17(70.8 \%)$ \\
\hline $3 b$ & $3(12.5 \%)$ \\
\hline 4 & $1(4.2 \%)$ \\
\hline $\mathrm{x}$ & $1(4.2 \%)$ \\
\hline \multicolumn{2}{|l|}{ N stage, n. (\%): } \\
\hline 0 & $6(25.0 \%)$ \\
\hline 1 & $12(50.0 \%)$ \\
\hline 2 & $2(8.3 \%)$ \\
\hline $\mathrm{x}$ & $4(16.7 \%)$ \\
\hline \multicolumn{2}{|l|}{ M stage, n. (\%): } \\
\hline 0 & $11(45.7 \%)$ \\
\hline 1 & $13(54.3 \%)$ \\
\hline \multicolumn{2}{|l|}{ Fuhrman grade, n. (\%): } \\
\hline 2 & $2(8.3 \%)$ \\
\hline 3 & $19(79.2 \%)$ \\
\hline NA & $3(12.5 \%)$ \\
\hline \multicolumn{2}{|l|}{ Major vein extension, n. (\%): } \\
\hline Absent & $10(41.7 \%)$ \\
\hline Present & $14(58.3 \%)$ \\
\hline \multicolumn{2}{|l|}{ Surgical margin, n. (\%): } \\
\hline R0 & $11(45.8 \%)$ \\
\hline R1 & $8(33.3 \%)$ \\
\hline $\mathrm{R} 2$ & $1(4.2 \%)$ \\
\hline $\mathrm{Rx}$ & $2(8.3 \%)$ \\
\hline
\end{tabular}

${ }^{\dagger}$ Six missing data existed.

\subsection{Local Treatment}

All the patients in this cohort underwent surgery including radical nephrectomy $(\mathrm{n}=21)$ and resection of renal tumor $(\mathrm{n}=3)$. Among them, $22(91.6 \%)$ were operated by open trans-abdominal or extra-peritoneal approach, 1 (4.2\%) was treated with laparoscopic nephrectomy, whereas 1 patient (4.2\%) underwent a robotic partial nephrectomy and had to be converted due to on cological reasons to open surgery. With respect to surgical margin (SM), 37.5\% (9/24) of patients were recorded as positive (R1 or R2). Of 19 patients with metastasis, resection of metastatic lesion was performed in 3 patients (15.8\%), of whom 2 patients had bone metastasis and 1 patient had liver metastasis. Among 5 patients with local recurrence $(20.8 \%)$, chemotherapy was given in all and resection of local recurrence was performed in 2 patients, of whom 1 received a combination of surgery and external beam therapy. Moreover, in total $25.0 \%$ (6/24) of patients underwentpalltiative radiation therapy for bone metastasis $(n=4)$ as well as brain $(n=$ 1) and retroperitoneal metastasis $(n=1)$,

\subsection{Systemic Therapy}

In total, 14 patients (58.3\%) were treated by chemotherapy in this study. Among 
them gemcitabine/cisplatin was dominantly given in 6 patients $(42.9 \%)$ with a median PFS of 6.3 months (range: 2.3-7.5), followed by gemcitabine/carboplatin in 3 patients $(21.4 \%)$. The other chemotherapeutic regimes were gemcitabine/ doxirubicin in 2 patients (14.3\%), gemcitabine mono in 2 patients $(14.3 \%)$ and Carboplatin monoin 1 patient (7.1\%), respectively. Targeted drugs were mostly given as $2^{\text {nd }}$ line therapy, including sunitinib $(n=3)$, sorafenib $(n=1)$ and pazopanib $(\mathrm{n}=1)$ were given to $5(20.8 \%)$ patients. Of these patients, 3 experienced previous chemotherapy failures. Only 1 patient with a CSS of 8.0 months received cytokine therapy of interferon-a plus interleukin-2. Furthermore, Nivolumab, the novel immunomodulator against programmed cell death 1 (PD-1) receptor, was given to 1 patient at a stage of T3aN1M1R1 after chemotherapy failure. This patient has survived for 9.5 months with no progression and is still under active surveillance currently.

\subsection{Oncological Outcome}

As shown in Figure 1, median CSS of the whole cohort from diagnosis of BM was 11.3 months (range: $1.2-52.0$ ), as well as the CSS rate at 1 and 3 years of this cohort were $50.0 \%$ and $33.3 \%$, respectively. Furthermore, CSS of the patients with CDRCC in different subgroups was shown in the Table 3.

\section{Discussions}

Because of the paucity of CDRCC, limited data concerning this disease were reported historically. So far, three series of CDRCC with a relatively large size from

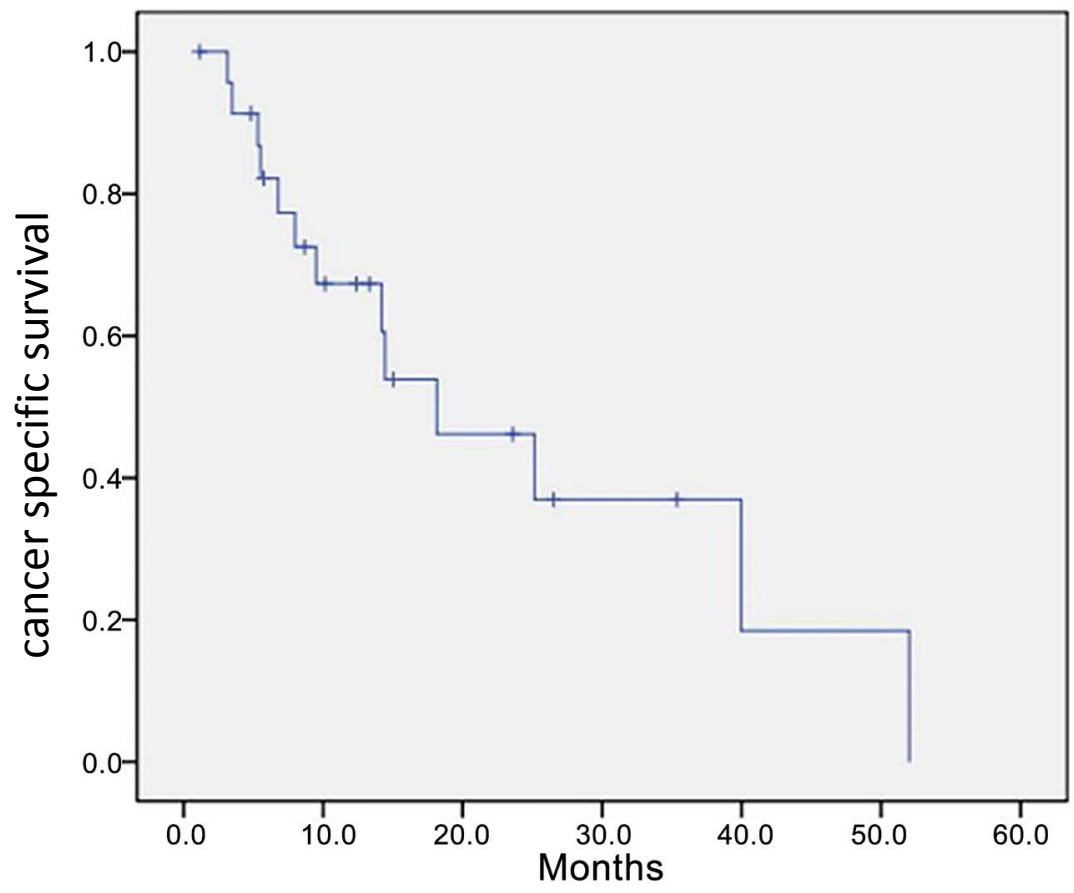

Figure 1. Kaplan-Meier curve of cancer specific survival (CSS) in 24 patients with collecting duct renal cell carcinoma (CDRCC). The median CSS was 11.3 months (range: 1.2 $52.0)$. 
Table 3. CSS of different subgroups in 24 patients with collecting duct renal cell carcinoma (CDRCC).

\begin{tabular}{|c|c|c|}
\hline Variable & No & Median, months ( range) \\
\hline \multicolumn{3}{|l|}{ Gender } \\
\hline Male & 16 & $9.2(3.2-40.0)$ \\
\hline Female & 8 & $14.2(1.2-52.0)$ \\
\hline \multicolumn{3}{|c|}{${ }^{\dagger}$ Symptomatic at presentation, n. (\%) } \\
\hline Yes & 11 & $14.4(1.2-35.4)$ \\
\hline No & 5 & $6.8(4.8-52.0)$ \\
\hline \multicolumn{3}{|c|}{ Local recurrence } \\
\hline Yes & 6 & $25.8(14.4-52.0)$ \\
\hline No & 18 & $8.3(1.2-35.4)$ \\
\hline \multicolumn{3}{|c|}{ Metastatic status } \\
\hline Yes & 19 & $14.2(3.5-52.0)$ \\
\hline Synchronic & 13 & $9.5(3.5-52.0)$ \\
\hline Metachronic & 6 & $24.4(13.3-40.0)$ \\
\hline No & 5 & $4.8(1.2-12.4)$ \\
\hline \multicolumn{3}{|c|}{ Number of metastases } \\
\hline Solitary & 7 & $15.0(5.5-40.0)$ \\
\hline Multiple & 12 & $13.8(3.5-52.0)$ \\
\hline \multicolumn{3}{|c|}{${ }^{\dagger}$ Regional nodal involvement: } \\
\hline Yes & 14 & $9.1(3.2-26.5)$ \\
\hline No & 6 & $19.8(5.5-40.0)$ \\
\hline \multicolumn{3}{|c|}{ Major vein extension: } \\
\hline Present & 10 & $8.3(1.2-23.6)$ \\
\hline Absent & 14 & $13.8(4.8-52.0)$ \\
\hline \multicolumn{3}{|c|}{ †Surgical margin, n. (\%): } \\
\hline Negative & 11 & $14.2(4.8-52.0)$ \\
\hline Positive & 9 & $8.7(1.2-25.2)$ \\
\hline \multicolumn{3}{|c|}{ Lymphadenectomy } \\
\hline Yes & 15 & $10.2(3.2-40.0)$ \\
\hline No & 9 & $14.4(1.2-52.0)$ \\
\hline \multicolumn{3}{|l|}{ Chemotherapy } \\
\hline Yes & 14 & $14.7(3.5-52.0)$ \\
\hline No & 10 & $6.1(1.2-26.5)$ \\
\hline \multicolumn{3}{|c|}{ Targeted Therapy } \\
\hline Yes & 5 & $14.2(5.8-26.5)$ \\
\hline No & 19 & $10.2(1.2-52.0)$ \\
\hline
\end{tabular}

${ }^{\dagger}$ Patients with missing or ambiguous data were excluded.

Europe, America and Japan were published, respectively. As shown in Table 4, these studies are conductive to draw the outlines of the characteristics of this rare disease [9] [10] [11].

In line with that of the European series, the incidence of the CDRCC was $0.5 \%$ - $0.6 \%$ in our study. However, CDRCC occurs more frequently in Black (1.2\%) than in White $(0.4 \%)$ in the American series. Some similarities were shown in the aforementioned series along with our series, which included a male predominance $(66.7 \%-75.6 \%)$, median age at diagnosis (58.2 - 64.0 years) and median tumor size $(5.5-6.1 \mathrm{~cm})$, respectively. Although a lower frequency of symptomatic patients was found in our series (45.7\%) compared to that in European series (72.8\%) and Japanese series (65.4\%), the actual frequency will be much higher in our series when taking $33.3 \%$ of missing data into consideration. 
Table 4. Dates reported in 3 large published series of collecting duct renal cell carcinoma (CDRCC).

\begin{tabular}{cccc}
\hline & Tokuda et al. & Karakiewicz et al. & Wright et al. \\
& {$[10]$} & {$[9]$} & {$[11]$} \\
\hline Publishing year & 2006 & 2007 & 2009 \\
Patients source & Japan & European & USA \\
Period of data extraction & $2001-2003$ & $1984-2001$ & $2001-2005$ \\
Number of patients & 81 & 41 & 160 \\
Median follow-up time, months (range) & $15.0(0.5-157.0)$ & $2.9(0.1-19.7)$ & 19.0 \\
Incidence (\%) & - & $0.6 \%$ & $1.2 \%$ in Blacks \\
& & & $0.4 \%$ in Whites \\
CSS rate at 1 year, \% & $69.0 \%$ & $86.1 \%$ & $70.0 \%$ \\
CSS rate at 3 years, \% & $45.3 \%$ & $\dagger 68.0 \%$ & $58.0 \%$ \\
Median age, years (range) & $58.2(26-79)$ & $64.0(40-90)$ & $62.0(-)$ \\
Male gender, n (\%) & $58(71.6 \%)$ & $31(75.6 \%)$ & $112(70 \%)$ \\
Symptomatic at presentation, n (\%) & $53(65.4 \%)$ & $59(72.8 \%)$ & - \\
Median tumor size, cm (range) & $6(1-15)$ & $6.1(2.0-18.0)$ & $\ddagger 5.9(-)$ \\
Advance T stage (T3 - 4), n (\%): & $46(57.0 \%)$ & $33(80.5 \%)$ & $53(33.1 \%)$ \\
Regional nodal involvement (N1-2), n (\%): & $27(33.3 \%)$ & $20(48.8 \%)$ & $24(15.0 \%)$ \\
Distance Metastasis (M1), n. (\%): & $26(32.1 \%)$ & $8(19.5 \%)$ & $44(27.5 \%)$ \\
High grade, n. (\%): & & & \\
Fuhrmann G3 - 4 & $80(98.8 \%)$ & $32(78.0 \%)$ & \\
Poorly/undifferentiated & - & - & $\$ 70.0 \%$ \\
Surgery for primary tumor, n. (\%): & $80(98.8 \%)$ & $41(100.0 \%)$ & $135 .(84.4 \%)$ \\
Chemotherapy, n. (\%) & $17(21.0 \%)$ & - & - \\
Immunotherapy, n (\%) & $34(42.0 \%)$ & - & - \\
\hline
\end{tabular}

${ }^{\dagger}$ Estimated by Kaplan Meier curve; ${ }^{\star}$ Mean value; $§$ Seventy of 100 patients with precise information of grad, ?missing data.

Including the present study, all the 3 series of CDRCC from western countries showed a similar rate of poorly differentiated disease ranging from $70.0 \%$ 79.2\%. However, this rate was extremely higher (98.8\%) in Japanese series, which might be explained by difference of genetics and environment. Compared to those of American series (57.0\% and 33.3\%) and Japanese series $(33.1 \%$ and $15.0 \%)$, the rate of advanced $\mathrm{T}$ stage (T3 - 4) and regional nodal involvement (N1-2) were much higher in our series $(87.5 \%$ and $58.3 \%)$ and the European series $(80.5 \%$ and $48.8 \%)$. In our series, an impressively higher rate of metastasis at presentation (54.3\%) was observed versus that of $19.5 \%-33.3 \%$ in the three series listed in the Table 4.

The CSS rates at 1 and 3 years in our series (50.0\% and 33.3\%) were slightly lower than those in Japanese series (69.0\% and $45.3 \%)$ and American series (70.0\% and 58.0\%). However, the CSS rates at 1 and 3 years were much higher (86.1\% and $68.0 \%)$ and had no difference compared to a matched series of clear cell RCC [9]. This phenomenon might be explained by a misclassification of some early cases in the European series, of which the data was extracted from 1984 to 2001. Because the diagnostic criteria of CDRCC was not defined accurately until a related criteria was proposed by Srigley and Eble in 1998 [15]. Moreover, the fact that $32.5 \%$ (39/120) of CDRCC patients were misclassified in the Japanese series after a central pathological review provided a circumstantial evidence for our assumption [10].

As shown in Table 3, the CSS of patients with female gender, N0 stage, ab- 
sence of veins extension, negative surgical margin as well as chemotherapy and targeted therapy were numerically longer. Unexpectedly, the CSS of patients without symptom at presentation, local recurrence and distant metastasis were shorter. Nevertheless, we soberly realized all these results were not sufficient to draw any conclusion if considering the small size and the limitations of the retrospective nature of the current series. All the patients, of whom the median CSS was 11.3 months in our study, underwent surgery. Although a sufficient sample from surgery is essential to increase the diagnostic accuracy of CDRCC, the effect of surgery on CDRCC is still controversial. Mejean, etc. declared radical surgery alone had no benefit on the survival of initially metastatic CDRCC and suggested a fine needle biopsy when a large renaltum or with suspicion of CDRCC on imaging, particularly on CT [12]. In our series, the median CSS of patients with lymphadenectomy was even numerically shorter than that of patients without lymphadenectomy, which might implicate an extensive surgical procedure should be given with caution for CDRCC patients. Currently, the chemotherapy of G/C regimen is proposed as a quasi-standard systemic treatment for CDRCC. Oudard, etc demonstrated a $26 \%$ response rate of G/C regimen for metastatic CDRCC in a prospective multicenter phase II study. [13] Similarly, 14 patients with a G/C predominant chemotherapy had a much longer median CSS (14.7 months) than that of the 10 patients without chemotherapy (6.1 months) in our series (Table 3). Only $20.8 \%$ (5/24) of patients were given targeted agents with a median CSS of 14.2 months versus that of 10.2 months in patients without targeted therapy. To date, the efficacy of targeted agents was only supported by a few small series and case report trials, some more welldesigned studies using targeted therapy in the treatment of CDRCC are warranted in the future. Limitations of our study are the small number of patients and its retrospective nature. However, because of the rarity of the disease lager cohorts are difficult to study.

In conclusions, CDRCC is a rare type of renal cell cancer with a very aggressive nature and a poor prognosis. A high percentage of CDRCC patients had advanced stage, high nuclear grade, regional nodal involvement and distant metastasis at presentation. To date, there is no standard protocol for the treatment of CDRCC. Current standard in systemic therapy of CDRCC is chemotherapy with gemcitabine and cisplatin.

\section{Compliance with Ethical Standards}

\section{Conflict of Interest}

All the co-authors declare that they have no conflict of interest.

\section{Ethical Approval}

All procedures performed in studies involving human participants were in accordance with the ethical standards of the institutional and/or national research committee and with the 1964 Helsinki Declaration and its later amendments or comparable ethical standards. 


\section{Informed Consent}

Informed consent was obtained from all individual participants included in the study.

\section{References}

[1] Rini, B.I., Campbell, S.C. and Escudier, B. (2009) Renal Cell Carcinoma. The Lancet, 373, 1119-1132.

[2] Ferlay, J., Steliarova-Foucher, E., Lortet-Tieulent, J., et al. (2013) Cancer Incidence and Mortality Patterns in Europe: Estimates for 40 Countries in 2012. European Journal of Cancer, 49, 1374-1403.

[3] Jonasch, E., Gao, J. and Rathmell, W.K. (2014) Renal Cell Carcinoma. BMJ, 349, 4797. https://doi.org/10.1136/bmj.g4797

[4] Algaba, F., Akaza, H., Lopez-Beltran, A., et al. (2011) Current Pathology Keys of Renal Cell Carcinoma. European Urology, 60, 634-643.

[5] Kuroda, N. and Tanaka, A. (2014) Recent Classification of Renal Epithelial Tumors. Medical Molecular Morphology, 47, 68-75. https://doi.org/10.1007/s00795-013-0033-0

[6] Dason, S., Allard, C., Sheridan-Jonah, A., et al. (2013) Management of Renal Collecting Duct Carcinoma: A Systematic Review and the McMaster Experience. Current Oncology, 20, e223-e232. https://doi.org/10.3747/co.20.1230

[7] Pickhardt, P.J., Siegel, C.L. and McLarney, J.K. (2001) Collecting Duct Carcinoma of the Kidney: Are Imaging Findings Suggestive of the Diagnosis? American Journal of Roentgenology, 176, 627-633. https://doi.org/10.2214/ajr.176.3.1760627

[8] Yoon, S.K., Nam, K.J., Rha, S.H., et al. (2006) Collecting Duct Carcinoma of the Kidney: CT and Pathologic Correlation. European Journal of Radiology, 57, 453460.

[9] Karakiewicz, P.I., Trinh, Q.D., Rioux-Leclercq, N., et al. (2007) Collecting Duct Renal Cell Carcinoma: A Matched Analysis of 41 Cases. European Urology, 52, 1140-1145.

[10] Tokuda, N., Naito, S., Matsuzaki, O., et al. (2004) Collecting Duct (Bellini Duct) Renal Cell Carcinoma: A Nation-Wide Survey in Japan. Journal of Urology, 171, 465-465.

[11] Wright, J.L., Risk, M.C., Hotaling, J. and Lin, D.W. (2009) Effect of Collecting Duct Histology on Renal Cell Cancer Outcome. Journal of Urology, 182, 2595-2599.

[12] Mejean, A., Roupret, M., Larousserie, F., Hopirtean, V., Thiounn, N. and Dufour, B. (2003) Is There a Place for Radical Nephrectomy in the Presence of Metastatic Collecting Duct (Bellini) Carcinoma? Journal of Urology, 169, 1287-1290. https://doi.org/10.1097/01.ju.0000050221.51509.f5

[13] Oudard, S., Banu, E., Vieillefond, A., et al. (2007) Prospective Multicenter Phase II Study of Gemcitabine plus Platinum Salt for Metastatic Collecting Duct Carcinoma: Results of a GETUG (Groupe d'Etudes des Tumeurs Uro-Genitales) Study. Journal of Urology, 177, 1698-1702.

[14] Procopio, G., Verzoni, E., Iacovelli, R., Colecchia, M., Torelli, T. and Mariani, L. (2012) Is There a Role for Targeted Therapies in the Collecting Ducts of Bellini Carcinoma? Efficacy Data from a Retrospective Analysis of 7 Cases. Clinical and Experimental Nephrology, 16, 464-467. https://doi.org/10.1007/s10157-012-0589-3

[15] Srigley, J.R. and Eble, J.N. (1998) Collecting Duct Carcinoma of Kidney. Seminars in Diagnostic Pathology, 15, 54-67. 
Submit or recommend next manuscript to SCIRP and we will provide best service for you:

Accepting pre-submission inquiries through Email, Facebook, LinkedIn, Twitter, etc. A wide selection of journals (inclusive of 9 subjects, more than 200 journals)

Providing 24-hour high-quality service

User-friendly online submission system

Fair and swift peer-review system

Efficient typesetting and proofreading procedure

Display of the result of downloads and visits, as well as the number of cited articles Maximum dissemination of your research work

Submit your manuscript at: http://papersubmission.scirp.org/

Or contact jet@scirp.org 